\title{
Which Sectors of a Modern Economy are most Central?
}

\author{
Florian Blöchl \\ Fabian J. Theis \\ Fernando Vega-Redondo \\ Eric O’N. Fisher
}

\author{
CESIFO WORKING PAPER NO. 3175 \\ CATEGORY 12: EMPIRICAL AND THEORETICAL METHODS \\ SEPTEMBER 2010
}
An electronic version of the paper may be downloaded
- from the SSRN website: Www.SSRN.com
- from the RePEc website: Www.RePEc.org
- from the CESifo website: www.CESifo-group.org/wp




\title{
Which Sectors of a Modern Economy are most Central?
}

\begin{abstract}
We analyze input-output matrices for a wide set of countries as weighted directed networks. These graphs contain only 47 nodes, but they are almost fully connected and many have nodes with strong self-loops. We apply two measures: random walk centrality and one based on count-betweenness. Our findings are intuitive. For example, in Luxembourg the most central sector is "Finance and Insurance" and the analog in Germany is "Wholesale and Retail Trade" or "Motor Vehicles", according to the measure. Rankings of sectoral centrality vary by country. Some sectors are often highly central, while others never are. Hierarchical clustering reveals geographical proximity and similar development status.
\end{abstract}

Florian Blöchl

Institute for Bioinformatics and Systems Biology

Helmholtz Center Munich

Ingolstädter Landstrasse 1

85764 Neuherberg

Germany

florian.bloechl@helmholtz-muenchen.de

Fernando Vega-Redondo

Economics Department

European University Institute

Via della Piazzuola 43

50133 Florence

Italy

Fernando.Vega@eui.eu
Fabian J. Theis

Institute for Bioinformatics and Systems Biology

Helmholtz Center Munich

Ingolstädter Landstrasse 1

85764 Neuherberg

Germany

fabian.theis@helmholtz-muenchen.de

Eric O’N. Fisher
Orfalea College of Business
California Polytechnic State University
1 Grand Avenue
San Luis Obispo, CA 93407
USA
eric.on.fisher@gmail.com




\section{Introduction}

Within a few weeks of the onset of the financial crisis in 2008 , the world economy had plunged into a severe global recession. The volume of international trade contracted sharply, and the world economy did not grow in 2009 for the first time since World War II. Many governments reacted with programs to mitigate the effects of the global downturn on their local economies. The United States spent \$3 billion on the Car Allowance Rebate System (CARS). Germany spent an even larger fraction of its national economy ( $€ 1.5$ billion) for a car scrappage program. What effect did these programs have? How did the supply of new cars work its way through the rest of the local economy?

Input-output analysis was designed to explore this kind of effect (ten Raa, 2006; Leontief, 1986). An input-output table is the matrix of the sales of goods and services between the different sectors of an economy. A sector is a fairly coarse level of aggregation; an industry is composed of many firms making an identical product, and a sector is composed of several industries making similar products. "Agriculture" and "Pharmaceuticals" are two typical sectors.

The techniques of input-output analysis have had ready applications in economic planning. It is alleged that Leontief (1986) developed aspects of input-output analysis during the Second World War partly as an attempt to help identify strategic weaknesses in the German economy. Ranking the influences of single sectors on national economic activity allows the identification of "key" sectors. For example, there has been much discussion about firms that are "too big to fail", and there was an implicit understanding that the bail-out of General Motors was necessary because of the importance of the automotive sector in the American economy.

In order to formalize such intuitive aspects, a deeper understanding of the structures of national economies seems to be warranted. Any national economy is a complex system in which many agents of different sizes interact by buying and selling goods and services. Schweitzer et al. (2009) suggest that an understanding of these interactions on a systemic level may be achieved by analyzing the underlying complex networks. During the last decade, network analysis has been applied successfully in physics, biology and the social sciences (Vega-Redondo, 2007; Barabási and Albert, 2002; Newman, 2003; Dorogovtsev and Mendes, 2003). The literature on economic networks is growing rapidly. Several authors have studied international trade networks. The early work used binary approaches 
(Garlaschelli and Loffredo, 2005; Serrano and Boguñá, 2003), but it soon became evident that trade ought to be analyzed as weighted graph (Bhattacharya et al., 2008; Fagiolo et al., 2009). Interpreting the gross domestic product (GDP) as a country's fitness, Garlaschelli and Loffredo (2004) proposed a model reproducing the topology of bilateral trade. A gravity model has been used to understand weighted trade networks (Bhattacharya et al., 2008). Recently, the "product space" (Hidalgo et al., 2007) and connections between banks (Iori et al., 2008) have been analyzed. Grassi (2010) studied information flow across board members of different firms, focusing on node centralities.

In fact, it is natural to interpret an input-output table as a network. Each sector corresponds to a vertex, and the flow of economic activity from one sector to another constitutes a weighted directed edge. In complex network theory, identifying "key" sectors and ranking the sectors' roles in an economy is the task of applying an appropriate measure of node centrality to this input-output graph.

Vertex centrality measures have been studied extensively for quite some time. Freeman (1977) introduced the notion of centrality in a graph; he defined the betweenness centrality of a node as the average number of shortest paths between pairs of other nodes that pass through it. Flow betweenness is based upon the maximum capacity of flows between nodes. It also includes contributions from some non-geodesic paths (Freeman et al., 1991). Another approach, closeness centrality, is commonly defined as the inverse of the mean geodesic distance from all nodes to a given one (Freeman, 1979). All these measures require flows in the network to know an ideal route from each source to each target, either in order to find a shortest path or to maximize flow. Addressing this potential deficiency, Newman (2005) defined random walk betweenness. He averages effective visits over all possible random walks in a network.

Three properties of input-output graphs make it hard to apply current centrality measures. First, at the usual level of aggregation, these networks are dense, typically almost completely connected. Thus applying measures based on shortest paths makes little sense. As the topology is nearly trivial, one needs to analyze edge weights. Second, they are directed; for example, in the United States in 2000, $\$ 13.5$ billion of rubber and plastic products were used in the production of motor vehicles, but only $\$ 53$ million of the output of the motor vehicle sector was used in the production of rubber and plastic products. Third, self-loops play a central role; in the same case, more than $60 \%$ of the total output of the cars sector was used as its own input. Some authors including White and Borgatti (1994) have 
extended centrality concepts to the directed case, but, to the best of our knowledge, no one until now has examined node centralities that incorporate self-loops. We derive two measures that are suited for such networks. Both rely on random walks and each has an economic interpretation.

The rest of the manuscript is structured as follows. The next section provides the basic concepts. The third section derives two centrality measures and shows their relation to economic theory. We contrast our two approaches using a small example. The forth section shows our empirical results using input-output data from a wide range of countries. The proposed measures reveal important aspects of different national economies. Moreover, the consistency of the data allows us to compare nodes' centralities across countries in an intuitive way. Finally, we present some brief conclusions and suggestions for future research. Implementations of the measures, the data and results are freely available at http://hmgu.de/cmb/ionetworks.

\section{Basic Concepts}

A graph $G=(V, E)$ consists of a set of vertices $V$ and a set of edges $E \subset V \times V$. In our case, each edge $(i, j) \in E$ is directed and assigned a non-negative real weight $a_{i j}$. By definition, the graph may contain self-loops. The number of vertices is denoted by $n$. We consider strongly connected graphs only; for any pair of nodes, there exists a directed path connecting them.

The graph can be represented by its $n \times n$ adjacency matrix $A=\left(a_{i j}\right)$, where the element $(i, j)$ represents the weight $a_{i j}$ of the edge from node $i$ to node $j$. To keep notation simple, we name the vertices by natural numbers, and we can identify them with according indices in the adjacency matrix. Missing edges correspond to zero weights in the adjacency matrix. Then, the out-degree of node $i$ is $k_{i}=\sum_{j=1}^{n} a_{i j}$. We denote the set of out-neighbors of $i$ by $N(i)=\{j \mid(i, j) \in E\}$.

\subsection{Input-Output Networks}

An input-output table $A$ is an adjacency matrix of a network whose vertices are the sectors of an economy. Its edges quantify the flow of economic activity between sectors. We focus on the table of intermediate inputs. It records only sales of goods and services by firms to other firms that are directly consumed or used up as inputs in the production process. It is not a closed system; the row and column 
sums are not equal. In national accounts, the total value of the gross output of a sector also includes sales for final demand: consumption, investment, government purchases, and net exports. The total value of gross inputs into a sector also includes payments to the factors of production: gross operating surplus, compensation to employees, and indirect business taxes (ten Raa, 2006).

\subsection{Random Walks}

The movement of goods between the sectors of an economy is best modeled as a random walk (Borgatti. 2005). In graph theory, a random walker starts out at a given position and repeatedly chooses an edge incident to the current position (Bollobás, 2001). These choices are made according to a probability distribution determined by the edge weights. The random walker proceeds for an arbitrarily long time or until a prescribed goal is reached.

An input-output table keeps track of the goods circulating through an economy, consisting of the outputs of a large number of firms in each sector. Hence, each entry is the statistical aggregation of many individual sales. We are interested in the transition probabilities of outputs produced by a sector. These can be obtained by normalizing the input-output matrix by its row sums.

Hence in the following we work with the transition matrix

$$
M=K^{-1} A,
$$

where $K$ is the diagonal matrix of the out-degrees $k_{i}$.

\section{Two Centrality Measures}

This section derives two centrality measures that are suited for weighted directed networks with selfloops. First, we explain their economic foundations. We relate the measures to other commonly used ones and also give a small example that contrasts them.

\subsection{Economic Intuition}

Following the ideas of Fischer Black (Black, 1987), we design both our centrality measures to quantify the response of sectors to an economic shock. Such a shock is a change in an exogenous variable 
that has repercussions on the endogenous variables under analysis (ten Raa, 2006). In input-output accounts, prices, technologies, firms, the distribution of profits, government policy, and the vector of final demands are exogenous, and the flows of commodities and corresponding payments between sectors are endogenous. Fischer Black hypothesized that the business cycle might arise because of the propagation of such shocks between the sectors of an economy (Black, 1987). Long and Plosser (1983) developed an elegant analysis of the United States economy based on this idea.

We trace supply shocks as they flow as intermediate inputs through the business sectors of an economy. Their random journeys end at the sector from which the extra output eventually satisfies final demand, which we interpret as the target of some random walk. Consider an extra dollar of production in the car sector - perhaps as a result of a government program - and the target "Food products". The initial output will be sold randomly to another sector, according to the pattern of sales in the input-output table. The original dollar of extra revenue will be paid to capital, labor, or indirect business taxes in "Motor vehicles". The supply shock becomes an input into some sector, and it will increase economic activity there by one dollar, akin to the conservation of current in a circuit. The new output again will be sold to some sector. Eventually this process will hit the target "Food products", where the extra dollar of output exits the system to satisfy final demand. Averaging over all initial shocks or over all pairs of shocks and targets, we define a node's centrality by how quickly or how frequently it is visited during this process.

Every economic transaction consists of a real and a monetary counterpart; thus when keeping track of the flow of goods and services from a source to a destination at the same time we monitor the flow of a dollar in payments from the destination back to the source.

\subsection{Random Walk Centrality}

Freeman's closeness centrality (Freeman, 1979) is widely used in social network analysis. It is commonly defined as the inverse of the mean geodesic distance from all nodes to a given one. Again, shortest paths make little sense in densely connected networks like input-output graphs. Moreover, they completely ignore self-loops.

In order to generalize the concept of closeness, distance between nodes has to be measured in a different way. We propose using the mean first passage time (MFPT). This distance is the measure of 
choice when dealing with random walk processes (Bollobás, 2001). The MFPT $H(s, t)$ from node $s$ to $t$ is the expected number of steps a random walker who starts at $s$ needs to reach $t$ for the first time:

$$
H(s, t):=\sum_{r=1}^{\infty} r \cdot P(s \stackrel{r}{\rightarrow} t) .
$$

Here $P(s \stackrel{r}{\rightarrow} t)$ is the probability that it takes exactly $r$ steps before the first arrival at $t$. Note that $H(t, t)=0$ since $P(t \stackrel{r}{\rightarrow} t)=0$ for $r \geq 1$. The MFPT is not symmetric, even for undirected graphs. This property reflects the fact that it is much more probable to travel from the periphery to the central nodes of a graph than to go the other way around.

We are interested in the first visit of the target node $t$. For calculations we can consider an absorbing random walk that by definition never leaves node $t$ once it is reached. It is thus appropriate to modify the transition matrix $M$ by deleting its $t-$ th row and column. This $(n-1) \times(n-1)$ matrix we denote by $M_{-t}$.

The element $(s, i)$ of the matrix $\left(M_{-t}\right)^{r-1}$ gives the probability of starting at $s$ and being at $i$ in $r-1$ steps, without ever having passed through the target node $t$. Consider a walk of exactly $r$ steps from $s$ that first arrives at $t$. Its probability is

$$
P(s \stackrel{r}{\rightarrow} t)=\sum_{i \neq t}\left(\left(M_{-t}\right)^{r-1}\right)_{s i} m_{i t}
$$

Plugging this into equation (2), we find

$$
H(s, t)=\sum_{r=1}^{\infty} r \sum_{i \neq t}\left(\left(M_{-t}\right)^{r-1}\right)_{s i} m_{i t}
$$

The infinite sum over $r$ is essentially the sum of the geometric series for matrices

$$
\sum_{r=1}^{\infty} r\left(M_{-t}\right)^{r-1}=\left(I-M_{-t}\right)^{-2}
$$


where $I$ is the $n-1$ dimensional identity matrix. Making this inversion is the reason for having deleted one row and column from the original transition matrix $M$. Lovász (1993) shows that $\left(I-M_{-t}\right)$ is invertible as long as there are no absorbing states, whereas $(I-M)$ is not. So

$$
H(s, t)=\sum_{i \neq t}\left(\left(I-M_{-t}\right)^{-2}\right)_{s i} m_{i t}
$$

For fast calculation, this can be easily vectorized as $H(., t)=\left(I-M_{-t}\right)^{-2} m_{-t}$. Here $H(., t)$ is the vector of mean first passage times for a walk that ends at target $t$ and $m_{-t}=\left(m_{1 t}, \ldots, m_{t-1, t}\right.$, $\left.m_{t+1, t}, \ldots, m_{n t}\right)^{\prime}$ is the $t-t h$ column of $M$ with the element $m_{t t}$ deleted. Further, let $e$ be an $n-1$ dimensional vector of ones. Then $m_{-t}=\left(I-M_{-t}\right) e$. Hence

$$
H(., t)=\left(I-M_{-t}\right)^{-1} e .
$$

This equation allows calculation of the MFPT matrix row-by-row with basic matrix operations only. Using the Sherman-Morrison formula (Golub and Van Loan, 1996), we can speed up the $n$ matrix inversions further.

Using the natural analogy with closeness centrality, we define random walk centrality as the inverse of the average mean first passage time to a given node:

$$
C_{r w}(i)=\frac{n}{\sum_{j \in V} H(j, i)}
$$

This measure is essentially proposed by Noh and Rieger (2004). Random walk centrality incorporates self-loops indirectly because they slow down the traffic between other nodes.

The economic interpretation of this measure is straightforward. Consider a supply shock that occurs with equal probability in any sector. Then a high random walk centrality of a sector means that it is very sensitive to supply conditions anywhere in the economy. Hence, if one could predict sectoral shocks accurately, one would short equity in a central sector and go long equity in a remote sector during an economic downturn. 


\subsection{Counting Betweeness}

Our second approach is inspired by Newman's random walk betweenness (Newman, 2005). We modify his concept slightly and generalize it to directed networks with self-loops. The proposed measure denoted as counting betweenness keeps track of how often a given node is visited on first-passage walks, averaged over all source-target pairs.

For source node $s$ and target $t \neq s$, the probability of being at node $i \neq t$ after $r$ steps is $\left(\left(M_{-t}\right)^{r}\right)_{s i}$. Then, the probability of going from $i$ to $j$ is $m_{i j}$. So the probability that a walker uses the edge $(i, j)$ immediately after $r$ steps is $\left(\left(M_{-t}\right)^{r}\right)_{s j} m_{i j}$. Summing over $r$, we can calculate how often the walker is expected to use this edge:

$$
\begin{aligned}
N_{i j}^{s t}: & =\sum_{r}\left(\left(M_{-t}\right)^{r}\right)_{s i} m_{i j}=m_{i j} \sum_{r}\left(\left(M_{-t}\right)^{r}\right)_{s i} \\
& =m_{i j}\left(\left(I-M_{-t}\right)^{-1}\right)_{s i}
\end{aligned}
$$

Notice that a walker never uses an edge $(i, j)$ if $j$ is not a neighbor of $i$ since the according transition probability is zero. The total number of times we go from $i$ to $j$ and back to $i$ is $N_{i j}^{s t}+N_{j i}^{s t}$. Here we differ from Newman (2005), who excludes walks that oscillate and thus counts only the net number of visits. On any walk from $s$ to $t$, we enter node $i \neq s, t$ as often as we leave it. Hence, on a path from $s$ to $t$, vertex $i$ is visted $\sum_{j \neq t}\left(N_{i j}^{s t}+N_{j i}^{s t}\right) / 2$ times. For source $s$, target $t$ and vertex $i \neq s, t$, we define:

$$
N^{s t}(i)=\sum_{j \neq t}\left(N_{i j}^{s t}+N_{j i}^{s t}\right) / 2
$$

We allow for self-loops, hence a random walker may follow the edge $(i, i)$, in which case the vertex $i$ is visited twice consecutively. Since it is possible that $i=j \neq t$, we have to divide by 2 in all cases.

There are two special cases. If $i=s$, then the walker visits node $s$ one extra time when it starts

$$
N^{s t}(s)=\sum_{j \neq t}\left(N_{s j}^{s t}+N_{j s}^{s t}\right) / 2+1
$$

Also, if $i=t$, then the walker is absorbed by vertex $t$ the first time it arrives there and

$$
N^{s t}(t)=1
$$


A

B

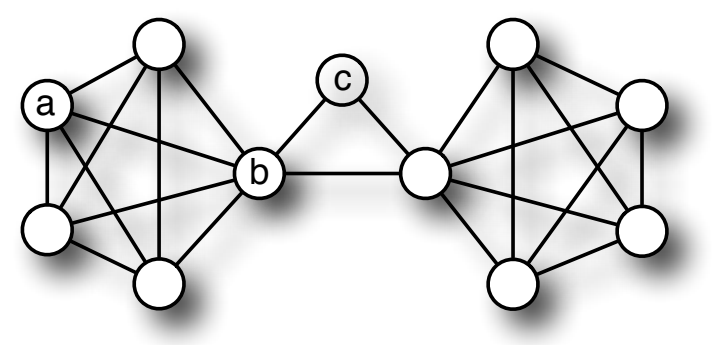

\begin{tabular}{c|ccc} 
& $\mathrm{a}$ & $\mathrm{b}$ & $\mathrm{c}$ \\
\hline Shortest-path betweenness $C_{s p}$ & 0.2 & 0.64 & 0.2 \\
Newman's betweenness $C_{N r w}$ & 0.27 & 0.67 & 0.33 \\
Random walk centrality $C_{r w}$ & 0.048 & 0.094 & 0.044 \\
Counting betweenness $C_{c}$ & 1.93 & 2.80 & 1.03
\end{tabular}

Figure 1: The network in (A) is taken from Newman (2005). (B) contrasts centrality measures calculated for selected nodes. Even though $c$ is topologically central, our measures do not rank it highly, in contrast to Newman's betweenness. Instead, they focus on how quickly or how frequently traffic within the network reaches a node. In a graph with two completely connected subcomponents, a slightly remote bridge-like node is not crossed over frequently.

We define the counting betweenness of node $i$ as the average of this quantity across all source-target pairs:

$$
C_{c}(i)=\frac{\sum_{s \in V} \sum_{t \in(V-\{s\})} N^{s t}(i)}{n(n-1)} .
$$

Counting betweenness can be used as a micro-foundation for the velocity of money. Consider a dollar of final demand that is spent with equal probability on the output of any sector, and assume that all transactions must be paid for with cash, not credit. Then the counting betweenness of sector $i$ is the expected number of periods that this dollar will spend there. If it is a high number, then that sector requires many transactions before the money is eventually returned to the household sector as a payment to some factor of production. If each transaction takes a fixed amount of time, then a sector with a high counting betweenness is a drag on the velocity of money in the economy.

\subsection{Illustrative Examples}

Before applying our measures to actual data, we demonstrate their behavior in small artificial examples. Figure 1(A) shows a graph introduced by Newman (2005) to illustrate different concepts of centrality. Here, all useful measures should obviously rank nodes of type $b$ most central. While 
A

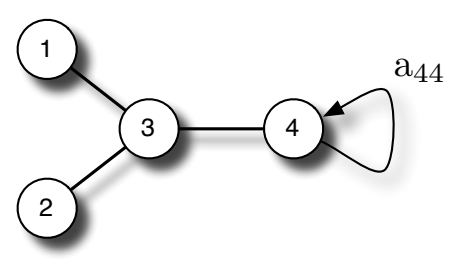

B

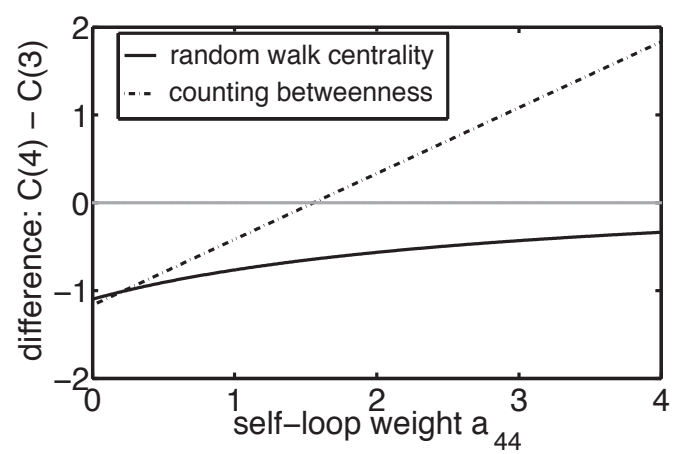

Figure 2: (A) This small network illustrates the importance of a self-loop. (B) This figure shows the difference between the centrality of node 4 and 3 as a function of the self-loop weight $a_{44}$. All other links have unit weight. Random walk centrality always ranks node 3 highest. Counting betweenness ranks node 4 higher when $a_{44}$ exceeds a threshold near 1.6. If the self-loop has a large weight, it takes a long time before a random walk leaves node 4 and enters the rest of the network.

concepts based on shortest paths do not account for the topologically central position of node $c$, Newman's betweenness gives a high centrality to $c$. In contrast, our measures both rank nodes of type $a$ higher than node $c$. A random walker spends a lot of time within the fully connected subgraph on the left and seldom crosses over the bridge-like node $c$. The former is why counting betweenness ranks node $a$ highly, and the latter is why random walk centrality gives it a high ranking.

Figure 2(A) shows a small network that illustrates the differences between our two measures. It emphasizes the role of a self-loop. Depending on the self-loop weight $\mathrm{a}_{44}$ attached to node 4 , either node 3 or 4 has the highest counting betweenness. In contrast, random walk centrality ranks node 3 highest, no matter the value of $\mathrm{a}_{44}$ is. Counting betweenness strongly emphasizes on the importance of self-loops which are considered only indirectly by random walk centrality. 


\section{The Central Sectors of Modern Economies}

Our data are the input-output accounts from the STAN database at the Organization for Economic Co-operation and Development (OECD), which are freely available at http://www. oecd.org/ sti/inputoutput/. They consist of 47 sectors and are benchmarked for 37 countries near the year 2000 (see Table 1 for a list). Each country's input-output table is one input-output graph. The analyzed countries account for more than $85 \%$ of world GDP.

The used data are consistent on three important dimensions. First, they are designed to be consistent across countries. Second, they are consistent with macroeconomic accounts; indeed, they maintain the national income accounting identities. Third, they are consistent across time; so we can compare Germany and the United States against themselves in two different benchmark years. The input-output accounts are reported in local currencies, but we have no need to use exchange rates or GDP deflators because we are only considering the unit-free transition matrices.

Some countries have sectors with no input or output. These arise because of data limitations in the local national accounts. The most serious case is the Russian Federation, where the OECD records output in only 22 sectors. Such sectors hinder the matrix inversion in equation (3). We therefore assign zero centrality to these nodes and remove them from the adjacency matrix. 
Table 1: The most central sectors in the economies benchmarked by the OECD.

\begin{tabular}{|c|c|c|}
\hline Country & Random Walk Centrality & Counting Betweenness \\
\hline Argentina & Food products & Health and social work \\
\hline Australia & Wholesale and retail trade & Wholesale and retail trade \\
\hline Austria & Wholesale and retail trade & Wholesale and retail trade \\
\hline Belgium & Wholesale and retail trade & Motor vehicles \\
\hline Brazil & Wholesale and retail trade & Food products \\
\hline Canada & Wholesale and retail trade & Motor vehicles \\
\hline China & Construction & Textiles \\
\hline Czech Republic & Wholesale and retail trade & Construction \\
\hline Denmark & Wholesale and retail trade & Food products \\
\hline Finland & Wholesale and retail trade & Communication equipment \\
\hline France & Construction & Motor vehicles \\
\hline Germany 1995 & Wholesale and retail trade & Motor vehicles \\
\hline Germany 2000 & Wholesale and retail trade & Motor vehicles \\
\hline Great Britain & Wholesale and retail trade & Health and social work \\
\hline Greece & Wholesale and retail trade & Wholesale and retail trade \\
\hline Hungary & Wholesale and retail trade & Motor vehicles \\
\hline Indonesia & Wholesale and retail trade & Textiles \\
\hline India & Land transport & Food products \\
\hline Ireland & Construction & Office machinery \\
\hline Israel & $\begin{array}{l}\text { Public admin. \& defence } \\
\text { social security }\end{array}$ & Health and social work \\
\hline Italy & Wholesale and retail trade & Wholesale and retail trade \\
\hline Japan & Other business activities & Motor vehicles \\
\hline Korea & Construction & Motor vehicles \\
\hline Luxembourg & Finance and insurance & Finance and insurance \\
\hline Netherlands & Wholesale and retail trade & Food products \\
\hline Norway & Wholesale and retail trade & Food products \\
\hline New Zealand & Wholesale and retail trade & Food products \\
\hline Poland & Wholesale and retail trade & Wholesale and retail trade \\
\hline Portugal & Wholesale and retail trade & Health and social work \\
\hline Russia & Wholesale and retail trade & Food products \\
\hline Slovakia & Wholesale and retail trade & Motor vehicles \\
\hline South Africa & $\begin{array}{l}\text { Public admin. \& defence } \\
\text { social security }\end{array}$ & $\begin{array}{l}\text { Public admin. \& defence } \\
\text { social security }\end{array}$ \\
\hline Spain & Wholesale and retail trade & Construction \\
\hline Sweden & Other business activities & Motor vehicles \\
\hline Switzerland & Wholesale and retail trade & Chemicals \\
\hline Turkey & Food products & Textiles \\
\hline Taiwan & Wholesale and retail trade & Office machinery \\
\hline USA 1995 & Wholesale and retail trade & Health and social work \\
\hline USA 2000 & $\begin{array}{l}\text { Public admin. \& defence } \\
\text { social security }\end{array}$ & $\begin{array}{l}\text { Public admin. \& defence } \\
\text { social security }\end{array}$ \\
\hline
\end{tabular}




\subsection{Results for Individual Countries}

Table 1 presents each country's most central sector with respect to our two measures. The complete results are available at http://hmgu.de/cmb/ionetworks. It is striking that "Wholesale and retail trade" is most frequently the sector with highest random walk centrality. In many economies, this sector has the highest share of final demand. Still, it is noteworthy that our normalization does not depend upon this fact. For example, in Germany in 2000, this sector accounts for $12 \%$ of final demand. "Real estate activities" is the second most important sector accounting for $9.6 \%$ of final demand, but its random walk centrality is ranked only eighth.

Counting betweenness reveals the importance of Nokia in Finland and the "Motor vehicles" sector in several advanced industrialized economies. Textiles play an important role in China, Indonesia, and Turkey, showing the significance of that manufacturing sector in countries with low wages. "Finance and insurance" is most central for Luxembourg. Finally, we note that "Public administration, defence, and compulsory social security" is most central in Israel, South Africa, and the US in 2000.

\subsection{Comparison of Different Countries}

The consistency of the data across countries allows us to immediately compare the centralities of sectors over different countries. We use a clustering technique to visualize our results. A clustering assigns a set of objects into groups according to some measure of similarity. The adjacency matrices are of dimension $2209=47 * 47$, but our focus on centrality reduces each economy to a vector of length 47 . Reducing the complex networks to a list of centrality values, we compress dramatically the relevant information. Moreover, we do not want to attach too much importance to the actual centrality numbers themselves, since we removed sectors without output in some countries. Instead, we are concerned with rankings. Thus, for us two economies are similar if their Spearman rank correlation of centralities across the sectors is high.

An easy and commonly used clustering technique is hierarchical clustering; Hastie et al. (2001) gives a good introduction. This iterative algorithm groups economies starting with the closest pair. In Figure $3 \mathrm{~A}$, Belgium and Spain are the two most similar countries; hence, they are on the lowest linked branches. Again, by similar we mean that the Spearman rank correlation of centralities across the sectors is high. We use complete linkage clustering to complete the dendrogram. This method defines 

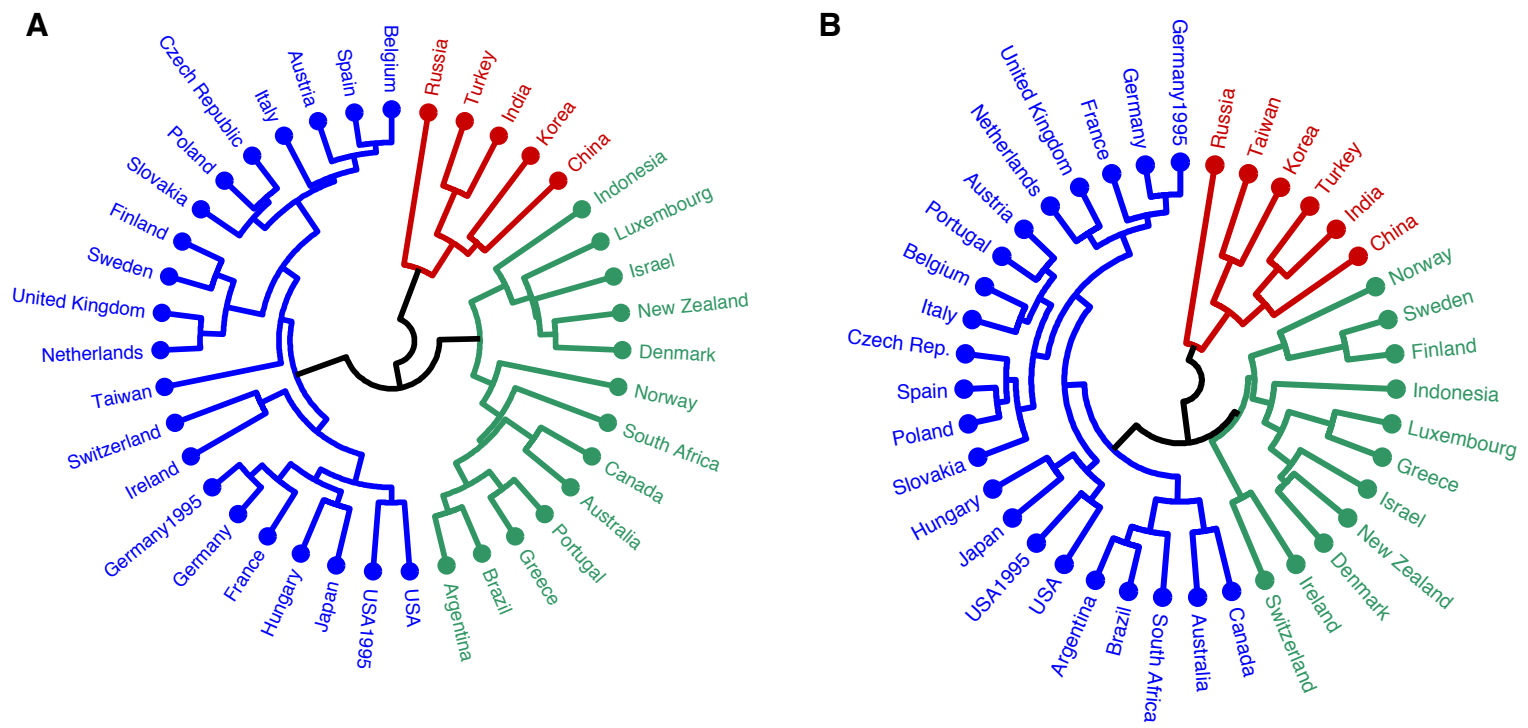

Figure 3: (A) gives a hierarchical clustering according to random walk centrality. Colors indicate the three important clusters: (1) the industrial countries from Belgium through the USA; (2) a mixed group from Argentina through Indonesia, where agriculture and primary products are important; and (3) a group of emerging economies from China through Russia. (B) shows clusterings according to counting betweenness. The clusterings according to the two measures are largely stable.

the distance between two sets $X$ and $Y$ as the maximum of the distances between any element in $X$ and any element in $Y$. The clustering algorithm proceeds iteratively by identifying nearest neighbors and showing the distance between them using branch heights. When all the initial singletons are linked, the algorithm stops.

Cutting the tree at a predefined threshold gives a clustering at the selected precision. At the threshold 0.65, we find three clusters in Figure 3A: (1) a group of advanced industrial economies ranging from Belgium through the United States; (2) a mixed group of countries where agriculture may be important; and (3) a group of rapidly emerging economies ranging from China through Russia.

Figure $3 \mathrm{~B}$ shows a clustering of economies based upon the similarity according to counting betweenness. Note that Taiwan is grouped quite differently in the two dendrograms. According to random walk centrality, it is in the middle of the advanced industrial economies. But in the clustering according to counting betweenness, it is a close neighbor of Korea, in the "Asian Tigers" sub-group of the emerging economies. An important reason for this difference is that Korea and Taiwan have food products and textiles sectors, both of which have strong self-loops. The clusterings capture the rem- 
nants of the historical development process in which both economies were based on manufacturing sectors just one generation ago.

It is reassuring that the clusterings are in large parts stable across the two measures. The groupings are natural; it is appropriate that the American and German economies, each sampled five years apart, are most closely related to their former selves. Leontief argued that the stability of input-output relations across time was a good empirical justification for using a fixed-coefficients technology in his original work (Leontief, 1986). These clusterings support his assertion.

\subsection{Two Detailed Comparisons}

Focusing on random walk centrality, we turn briefly to a detailed study of two different pairs of similar economies. Tables 2 and 3 look into the details inherent in the sector's rankings that arise from that measure.

The two nearest neighbors in Figure 3(A) are Belgium and Spain. Both are advanced economies. Table 2 reports the ten most central sectors in each country. There is a remarkable similarity between the flow of intermediate inputs in these economies. The most central sectors in both countries are "Retail trade" and "Construction". These sectors are notoriously pro-cyclical, and random walk centrality shows that fact clearly.

Table 2: Two advanced economies that are similar in their nodes' rankings according to random walk centrality.

\begin{tabular}{ccc} 
Rank & Sector in Belgium & Sector in Spain \\
\hline 1 & Wholesale \& retail trade & Wholesale \& retail trade \\
2 & Construction & Construction \\
3 & Other business activities & Hotels and restaurants \\
4 & Food products & Other business activities \\
5 & Chemicals & Food products \\
6 & Hotels and restaurants & Real estate activities \\
7 & Travel agencies & Travel agencies \\
8 & Motor vehicles & Other social services \\
9 & Agriculture & Motor vehicles \\
10 & Health and social work & Agriculture
\end{tabular}


A
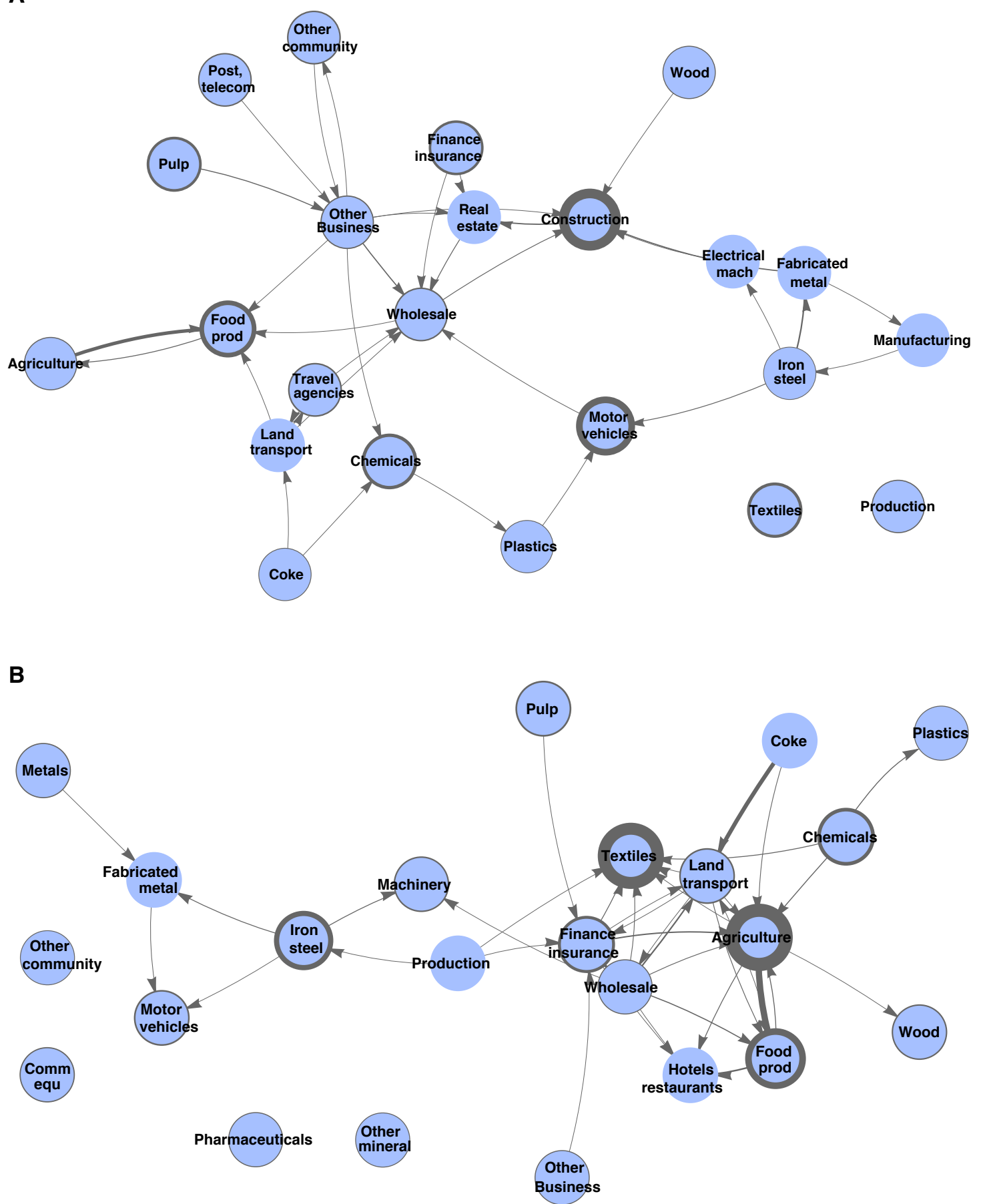

Figure 4: The core of the input-output networks of (A) Spain and (B) Turkey. For this illustration, the graphs were thresholded. Edge thickness corresponds to the observed commodity flows, the thickness of the nodes' strokes encodes self-loop weight. 
India and Turkey are two developing countries that cluster together. This pair is somewhat less similar than Belgium and Spain; in Figure 3(B), the length of the branch that brings them together is twice as high as that for Belgium and Spain. "Food products", "Construction", and "Hotels and restaurants" all have high centrality rankings. These rankings seem to indicate that the sectoral composition of business cycles is somewhat different in an emerging economy.

Table 3: Two emerging economies that are similar in their nodes' rankings according to random walk centrality.

\begin{tabular}{ccc} 
Rank & Sector in India & Sector in Turkey \\
\hline 1 & Land transport & Food products \\
2 & Food products & Wholesale \& retail trade \\
3 & Agriculture & Construction \\
4 & Construction & Hotels and restaurants \\
5 & Hotels and restaurants & Agriculture \\
6 & Textiles & Finance \& insurance \\
7 & Health and social work & Textiles \\
8 & Wholesale \& retail trade & Land transport \\
9 & Chemicals & Travel agencies \\
10 & Production & Machinery and equipment
\end{tabular}

Figure 4 shows the core of the input-output networks of Spain and Turkey.

\section{Conclusion}

We described two vertex centrality measures that are based on random walks. A node's random walk centrality is the inverse of the mean number of steps it takes to reach it, averaged over all starting nodes. Counting betweenness measures the expected number of times that a random walk passes a certain node before it reaches its target, averaged over all pairs of sources and targets. Both measures allow the analysis of weighted directed networks with self-loops. The need for such measures arises from interpreting economic questions within a graph-theoretic framework. We expect that our techniques will be useful for analyzing payment networks and other financial systems. Moreover, any coarsely grained network - such as one describing clubs or teams, not just individuals themselves - will have important self-loops. Our measures will serve well to describe this kind of network architecture. We agree with Estrada et al. (2009) that there is no best measure of centrality, and we 
followed their advice and developed two measures that are based on economic theory. We verified our approaches with the application to real complex networks.

We directed our attention to the flow of economic activity as intermediate inputs before they exited the system for use in final demand. Our measures identify a central node as a sector that is affected most immediately or most strongly by a random supply shock. Applying these measures to OECD data revealed important aspects of different national economies. We took full advantage of the consistency of the data across countries and gave clusterings of the sector' rankings in these networks. These were intuitive, grouping countries with similar levels of development.

To the best of our knowledge, our hierarchical clustering based on node centralities was the first attempt to quantitatively compare properties of individual nodes which are linked differently in multiple instances of connecting graphs. This was possible because we had the same sectors trading goods and services in many countries. Hence, we believe this data set is a rich source for other researchers in the field.

There is a lot more work to be done in this area. The theory of networks has flourished in the last decade, and consistent international data have also become widely available during this time. These data have a time dimension, and one may also begin to study the temporal evolution of economic networks. This may well enable researchers to connect generative models of networks with observations from the real world. Comparisons of extended versions of these network architectures may shed light on the oldest question in all of economics: Why are some countries poor, while others are prosperous?

\section{Acknowledgements}

The authors thank Carsten Marr and Dominik Wittmann for critical proofreading. E. Fisher thanks the ETH at Zurich and CES at Munich for the hospitality that allowed this work to be completed. This work was partially supported by the Helmholtz Association (project 'CoReNe') and the Federal Ministry of Education and Research (BMBF) in its MedSys initiative (project 'SysMBo'). 


\section{References}

Barabási, A.-L. and R. Albert (2002). Statistical mechanics of complex networks. Rev. Mod. Phys 74(1), 47-97.

Bhattacharya, K., G. Mukherjee, J. Saramaki, K. Kaski, and S. S. Manna (2008). The international trade network: weighted network analysis and modelling. J. Stat. Mech. 2008(02), P02002.

Black, F. (1987). Business Cycles and Equilibrium. Basil Blackwell, New York.

Bollobás, B. (2001). Random graphs. Cambridge Studies in Advanced Mathematics.

Borgatti, S. P. (2005). Centrality and network flow. Social Networks 27(1), 55-71.

Dorogovtsev, S. N. and J. F. Mendes (2003). Evolution of Networks. Oxford University Press.

Estrada, E., D. J. Higham, and N. Hatano (2009). Communicability betweenness in complex networks. Physica A 388(5), $764-774$.

Fagiolo, G., J. Reyes, and S. Schiavo (2009). World-trade web: Topological properties, dynamics, and evolution. Phys. Rev. E 79(3), 036115.

Freeman, L. C. (1977). A set of measures of centrality based on betweenness. Sociometry 40, 31-41.

Freeman, L. C. (1979). Centrality in social networks: Conceptual clarification 1. Social Networks 1(4), 215-239.

Freeman, L. C., S. P. Borgatti, and D. R. White (1991). Centrality in valued graphs: A measure of betweenness based on network flow. Social Networks 13(2), 141-154.

Garlaschelli, D. and M. I. Loffredo (2004). Fitness-dependent topological properties of the world trade web. Phys. Rev. Lett. 93, 188701.

Garlaschelli, D. and M. I. Loffredo (2005). Structure and evolution of the world trade network. Physica A 355(1), 138 - 144.

Golub, G. H. and C. F. Van Loan (1996). Matrix computations. Johns Hopkins University Press. 
Grassi, R. (2010). Vertex centrality as a measure of information flow in italian corporate board networks. Physica A 389, 2455-2464.

Hastie, T., R. Tibshirani, and J. Friedman (2001). The Elements of Statistical Learning. Springer.

Hidalgo, C. A., B. Klinger, B. Albert-Lázló, and R. Hausmann (2007). The product space conditions the development of nations. Science 317, 482-487.

Iori, G., G. D. Masi, O. V. Precup, G. Gabbi, and G. Caldarelli (2008). A network analysis of the italian overnight money market. J. Econ. Dyn. and Control 32(1), 259 - 278.

Leontief, W. (1986). Input-Output Economics (2nd ed.). Oxford University Press, New York.

Long, J. B. and C. I. Plosser (1983). Real business cycles. J. of Political Economy 91, 39-69.

Lovász, L. (1993). Random walks on graphs: a survey. Combinatorics 2(80), 1-46.

Newman, M. E. J. (2003). The structure and function of complex networks. SIAM Review 45(2), 167256.

Newman, M. E. J. (2005). A measure of betweenness centrality based on random walks. Social Networks 27(1), 39-54.

Noh, J. D. and H. Rieger (2004). Random walks on complex networks. Phys. Rev. Lett. 92(11), 118701

Schweitzer, F., G. Fagiolo, D. Sornette, F. Vega-Redondo, A. Vespignani, and D. R. White (2009, July). Economic networks: the new challenges. Science 325(5939), 422-425.

Serrano, M. A. and M. Boguñá (2003). Topology of the world trade web. Phys. Rev. E 68(1), 015101. ten Raa, T. (2006). The Economics of Input-Output Analysis. Cambridge Books, Cambridge University Press.

Vega-Redondo, F. (2007). Complex Social Networks. Cambridge University Press.

White, D. R. and S. P. Borgatti (1994). Betweenness centrality measures for directed graphs. Social Networks 16(4), 335-346. 


\section{CESifo Working Paper Series}

for full list see www.cesifo-group.org/wp

(address: Poschingerstr. 5, 81679 Munich, Germany, office@cesifo.de)

3111 Johannes Metzler and Ludger Woessmann, The Impact of Teacher Subject Knowledge on Student Achievement: Evidence from Within-Teacher Within-Student Variation, June 2010

3112 Leif Danziger, Uniform and Nonuniform Staggering of Wage Contracts, July 2010

3113 Wolfgang Buchholz and Wolfgang Peters, Equity as a Prerequisite for Stable Cooperation in a Public-Good Economy - The Core Revisited, July 2010

3114 Panu Poutvaara and Olli Ropponen, School Shootings and Student Performance, July 2010

3115 John Beirne, Guglielmo Maria Caporale and Nicola Spagnolo, Liquidity Risk, Credit Risk and the Overnight Interest Rate Spread: A Stochastic Volatility Modelling Approach, July 2010

3116 M. Hashem Pesaran, Predictability of Asset Returns and the Efficient Market Hypothesis, July 2010

3117 Dorothee Crayen, Christa Hainz and Christiane Ströh de Martínez, Remittances, Banking Status and the Usage of Insurance Schemes, July 2010

3118 Eric O’N. Fisher, Heckscher-Ohlin Theory when Countries have Different Technologies, July 2010

3119 Huw Dixon and Hervé Le Bihan, Generalized Taylor and Generalized Calvo Price and Wage-Setting: Micro Evidence with Macro Implications, July 2010

3120 Laszlo Goerke and Markus Pannenberg, 'Take it or Go to Court' - The Impact of Sec. 1a of the German Protection against Dismissal Act on Severance Payments -, July 2010

3121 Robert S. Chirinko and Daniel J. Wilson, Can Lower Tax Rates be Bought? Business Rent-Seeking and Tax Competition among U.S. States, July 2010

3122 Douglas Gollin and Christian Zimmermann, Global Climate Change and the Resurgence of Tropical Disease: An Economic Approach, July 2010

3123 Francesco Daveri and Maria Laura Parisi, Experience, Innovation and Productivity Empirical Evidence from Italy's Slowdown, July 2010

3124 Carlo V. Fiorio and Massimo Florio, A Fair Price for Energy? Ownership versus Market Opening in the EU15, July 2010

3125 Frederick van der Ploeg, Natural Resources: Curse or Blessing?, July 2010 
3126 Kaisa Kotakorpi and Panu Poutvaara, Pay for Politicians and Candidate Selection: An Empirical Analysis, July 2010

3127 Jun-ichi Itaya, Makoto Okamura and Chikara Yamaguchi, Partial Tax Coordination in a Repeated Game Setting, July 2010

3128 Volker Meier and Helmut Rainer, On the Optimality of Joint Taxation for NonCooperative Couples, July 2010

3129 Ryan Oprea, Keith Henwood and Daniel Friedman, Separating the Hawks from the Doves: Evidence from Continuous Time Laboratory Games, July 2010

3130 Mari Rege and Ingeborg F. Solli, The Impact of Paternity Leave on Long-term Father Involvement, July 2010

3131 Olaf Posch, Risk Premia in General Equilibrium, July 2010

3132 John Komlos and Marek Brabec, The Trend of BMI Values by Centiles of US Adults, Birth Cohorts 1882-1986, July 2010

3133 Emin Karagözoğlu and Arno Riedl, Information, Uncertainty, and Subjective Entitlements in Bargaining, July 2010

3134 John Boyd, Gianni De Nicolò and Elena Loukoianova, Banking Crises and Crisis Dating: Theory and Evidence, July 2010

3135 Michael R. Baye, Dan Kovenock and Casper G. de Vries, The Herodotus Paradox, July 2010

3136 Martin Kolmar and Hendrik Rommeswinkel, Group Contests with Complementarities in Efforts, July 2010

3137 Carolina Manzano and Xavier Vives, Public and Private Learning from Prices, Strategic Substitutability and Complementarity, and Equilibrium Multiplicity, July 2010

3138 Axel Löffler, Gunther Schnabl and Franziska Schobert, Inflation Targeting by Debtor Central Banks in Emerging Market Economies, July 2010

3139 Yu-Fu Chen and Michael Funke, Global Warming and Extreme Events: Rethinking the Timing and Intensity of Environmental Policy, July 2010

3140 Lawrence M. Kahn, Labor Market Policy: A Comparative View on the Costs and Benefits of Labor Market Flexibility, July 2010

3141 Ben J. Heijdra, Jochen O. Mierau and Laurie S.M. Reijnders, The Tragedy of Annuitization, July 2010

3142 Erkki Koskela, Outsourcing Cost and Tax Progression under Nash Wage Bargaining with Flexible Outsourcing, July 2010 
3143 Daniel Osberghaus and Christiane Reif, Total Costs and Budgetary Effects of Adaptation to Climate Change: An Assessment for the European Union, August 2010

3144 Philip E. Graves, Benefit-Cost Analysis of Environmental Projects: A Plethora of Systematic Biases, August 2010

3145 Sabrina Di Addario and Daniela Vuri, Entrepreneurship and Market Size. The Case of Young College Graduates in Italy, August 2010

3146 Shoshana Amyra Grossbard and Alfredo Marvăo Pereira, Will Women Save more than Men? A Theoretical Model of Savings and Marriage, August 2010

3147 Jarko Fidrmuc, Time-Varying Exchange Rate Basket in China from 2005 to 2009, August 2010

3148 Ilja Neustadt and Peter Zweifel, Is the Welfare State Sustainable? Experimental Evidence on Citizens' Preferences for Redistribution, August 2010

3149 Marcus Dittrich and Andreas Knabe, Wage and Employment Effects of Non-Binding Minimum Wages, August 2010

3150 Shutao Cao, Enchuan Shao and Pedro Silos, Fixed-Term and Permanent Employment Contracts: Theory and Evidence, August 2010

3151 Ludger Woessmann, Cross-Country Evidence on Teacher Performance Pay, August 2010

3152 Lorenzo C. G. Pozzi, Casper G. de Vries and Jorn Zenhorst, World Equity Premium Based Risk Aversion Estimates, August 2010

3153 Volker Grossmann, Thomas M. Steger and Timo Trimborn, Dynamically Optimal R\&D Subsidization, August 2010

3154 Alexander Haupt, Tim Krieger and Thomas Lange, A Note on Brain Gain and Brain Drain: Permanent Migration and Education Policy, August 2010

3155 António Afonso and Christophe Rault, Long-run Determinants of Sovereign Yields, August 2010

3156 Franziska Tausch, Jan Potters and Arno Riedl, Preferences for Redistribution and Pensions. What can we Learn from Experiments?, August 2010

3157 Martin Kolmar and Andreas Wagener, Inefficient Group Organization as Optimal Adaption to Dominant Environments, August 2010

3158 Kai Carstensen, Klaus Wohlrabe and Christina Ziegler, Predictive Ability of Business Cycle Indicators under Test: A Case Study for the Euro Area Industrial Production, August 2010 
3159 Horst Rottmann and Timo Wollmershäuser, A Micro Data Approach to the Identification of Credit Crunches, August 2010

3160 Philip E. Graves, Appropriate Fiscal Policy over the Business Cycle: Proper Stimulus Policies Can Work, August 2010

3161 Michael Binder and Marcel Bluhm, On the Conditional Effects of IMF Program Participation on Output Growth, August 2010

3162 Michael Binder, Qianying Chen, and Xuan Zhang, On the Effects of Monetary Policy Shocks on Exchange Rates, August 2010

3163 Felix J. Bierbrauer, On the Optimality of Optimal Income Taxation, August 2010

3164 Nikolaus Wolf, Europe's Great Depression - Coordination Failure after the First World War, September 2010

3165 Dan Kovenock and Brian Roberson, Conflicts with Multiple Battlefields, September 2010

3166 Jean-Pierre Ponssard and Catherine Thomas, Capacity Investment under Demand Uncertainty. An Empirical Study of the US Cement Industry, 1994-2006, September 2010

3167 Jørgen Juel Andersen, Jon H. Fiva and Gisle James Natvik, Voting when the Stakes are High, September 2010

3168 Michael Hoel, Is there a Green Paradox?, September 2010

3169 Scott Alan Carson, Nineteenth Century US African-American and White Female Statures: Insight from US Prison Records, September 2010

3170 Gil S. Epstein, Yosef Mealem and Shmuel Nitzan, Political Culture and Discrimination in Contests, September 2010

3171 Sara Fisher Ellison, Jeffrey Greenbaum and Wallace P. Mullin, Diversity, Social Goods Provision, and Performance in the Firm, September 2010

3172 Silvia Dominguez-Martinez, Randolph Sloof and Ferdinand von Siemens, Monitoring your Friends, not your Foes: Strategic Ignorance and the Delegation of Real Authority, September 2010

3173 Marcus Dittrich and Beate Schirwitz, Union Membership and Employment Dynamics: A Note, September 2010

3174 Francesco Daveri, Paolo Manasse and Danila Serra, The Twin Effects of Globalization - Evidence from a Sample of Indian Manufacturing Firms, September 2010

3175 Florian Blöchl, Fabian J. Theis, Fernando Vega-Redondo and Eric O’N. Fisher, Which Sectors of a Modern Economy are most Central?, September 2010 